\title{
Amenaza terrorista de Boko Haram, el rol de las Naciones Unidas en el conflicto armado en Nigeria ${ }^{1}$
}

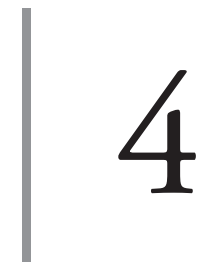

https://doi.org/10.21830/9789585318328.04

\author{
Angie Julieth Arenas Piedrahita ${ }^{2}$ \\ Escuela Militar de Cadetes "General José María Córdova”
}

\section{Resumen}

El presente capítulo analiza el rol de la ONU en la resolución del conflicto armado nigeriano, a partir del estudio del nacimiento y evolución de la organización terrorista Boko Haram y su impacto en la región. Para ello, se empleó una metodología de estudio de caso, con enfoque cualitativo y alcance explicativo. Dentro de los principales hallazgos de la investigación cabe destacar el papel limitado de la Organización en las etapas iniciales del conflicto, la internacionalización de este como parte del juego de poder entre las potencias del sistema internacional, y la preponderancia de los actores no estatales en la visibilización del drama humano ocasionado por las acciones del Estado Islámico en África Occidental. De allí, que se plantee la necesidad de reestructurar el Sistema de Naciones Unidas desde su misionalidad y alcance real, y replantear la lucha contra el terrorismo internacional desde un enfoque de derechos humanos.

Palabras clave: Boko Haram; comunidad internacional; conflicto armado; Nigeria; terrorismo; violencia.

1 Este capítulo hace parte de los resultados del proyecto de investigación "Mecanismos del sistema de Naciones Unidas para la resolución de conflictos armados contemporáneos", del Grupo de Investigación en Ciencias Militares de la Escuela Militar de Cadetes "General José María Córdova, registrado con el código COL0082556 de Minciencias. Los puntos de vista y los resultados de este artículo pertenecen al autor y no reflejan necesariamente los de las instituciones participantes.

2 Profesional en Relaciones Internacionales y Estudios Políticos (Universidad Militar Nueva Granada). Magíster en Asuntos Internacionales con énfasis en resolución de conflictos armados (Universidad Externado de Colombia y Escuela de Asuntos Internacionales y Políticas Públicas de Columbia University). Docente universitaria. Sus áreas de investigación son: filosofía política, gobernanza global, teorías de Relaciones Internacionales, seguridad internacional, conflictos armados contemporáneos, y Bioética global. ORCID: https://orcid.org/0000-0002-4054-6417 - Contacto: angie.arenas@esmic.edu.co 


\section{Introducción}

Dentro de las causas que originan la aparición de Boko Haram en Nigeria —alrededor del año 2002- es posible identificar distintos factores que sirven como catalizadores del desarrollo de cualquier insurgencia, tales como los conflictos religiosos y étnicos, los conflictos coloniales, en el caso de África, y los conflictos políticos y de dominio territorial, los cuales se acumulan y se solapan dando lugar a este tipo de fenómeno (Torres, 2015).

Esta organización, que constituye el centro del conflicto que desde inicios del siglo XXI azota la región del lago Chad, tiene su foco principal de actuación en el país africano de Nigeria, uno de los más poblados del mundo actualmente, con una de las economías de mayor crecimiento exponencial en el continente africano.

Haciendo un breve recuento histórico, entre el siglo IX y el siglo XVI, la religión islámica, proveniente de lo que hoy se conoce como Arabia Saudita, se fue abriendo paso lentamente en África occidental subsahariana, de la mano de los comerciantes árabes de la región, generando un número limitado de conversos quienes se dedicaron principalmente a la administración, es decir, que no insistieron de forma excesiva en la expansión del islam, y mucho menos en erradicar las prácticas preislámicas asentadas en la región, debido, en gran medida, al arraigo de los gobernantes locales.

Inicialmente, las comunidades musulmanas no tuvieron mayores reparos al someterse a gobiernos laicos o de otras religiones, siempre y cuando estos les permitieran seguir el modelo del profeta Mahoma, "cuyas enseñanzas, ejemplificadas en la vida cotidiana de los musulmanes, serían, al fin y a la postre, el mejor modo de atraer a los incrédulos" (Torres, 2015, p. 1).

No obstante, a partir del siglo XVII, y durante los siguientes 200 años, se produjo un cambio significativo en el enfoque de los movimientos reformistas de orientación musulmana, pasando de la tradición pacífica de coexistencia con los no creyentes, a una yihadista mucho menos tolerante.

Un análisis más profundo muestra que las diferencias entre las distintas comunidades, más allá de haber sido ocasionadas por un conflicto religioso, se relacionan, más bien, con la actuación política del gobierno nigeriano, 
la cual condujo a un quebrantamiento entre los diversos grupos (Torregrosa et al., 2016).

Es en este contexto que surgió la lucha armada de Boko Haram contra el Estado nigeriano, que ha cobrado la vida de miles de personas y sembrado terror en el occidente de África, convirtiéndose en un conflicto internacional que ha tocado los intereses de diversas potencias, especialmente desde el punto de vista económico.

Dicho lo anterior, este capítulo analiza el fenómeno terrorista de Boko Haram desde diferentes miradas — nacional, regional e internacional-, partiendo del hecho de que, a pesar del alto grado de letalidad de esta organización, las acciones emprendidas por la comunidad internacional, en cabeza de la Organización de las Naciones Unidas, han sido relativamente escasas, de manera que esta amenaza se encuentra aún latente después de más de una década de su nacimiento.

Así pues, el presente texto estará orientado por las siguientes preguntas: ¿cuáles son los orígenes de Boko Haram y el consecuente conflicto armado en Nigeria?, ¡cuáles son los intereses y actores involucrados en dicho conflicto?, ¿cuál ha sido el papel de la comunidad internacional, en cabeza de la ONU, frente a la necesidad de combatir esta amenaza?

Para dar respuesta a estas cuestiones, el presente capítulo estará dividido en tres secciones. En primer lugar, se hará una breve contextualización de los principales hitos que marcaron el nacimiento y consolidación de la organización, así como los principales actores e intereses involucrados; en segundo lugar, se analizará el rol de la Organización de Naciones Unidas en el marco de las confrontaciones; y, en última instancia, se presentarán algunas reflexiones finales.

\section{Conflicto armado en Nigeria}

\section{Algunos antecedentes}

Tal como afirman Torregrosa y otros (2016), como preámbulo para explicar el origen de Boko Haram, es conveniente señalar que a pesar del tiempo que la organización lleva operando en Nigeria y otros territorios vecinos, en la actualidad es complejo encontrar información fidedigna y consistente con la cual definir de manera correcta al grupo terrorista. 
Esto, debido a una multiplicidad de motivos entre los que se destacan la poca información que transmite la Policía a este respecto, el hecho de que muchos oficiales y personas con altos cargos en el Gobierno están comprados por la organización, y la debilidad de los servicios de seguridad, en general, para hacer frente a la amenaza que representa este grupo terrorista (Torregrosa et al., 2016).

Así que, para comprender este fenómeno en su totalidad, es necesario hacer una breve contextualización del marco histórico y geográfico en el que surgió la organización, así como los factores sociales, políticos y religiosos que determinaron el curso del conflicto que hoy se encuentra vigente.

Situado en África occidental, más específicamente en la costa del Golfo de Guinea, Nigeria es un país que actualmente cuenta con un sistema de gobierno propio de una república federal presidencialista, el cual atravesó por un periodo de colonia británica, que posteriormente fue controlada por un régimen militar, hasta convertirse en un país que logró el establecimiento de la democracia, en 1999 (Torregrosa et al., 2016).

Este país, que ha logrado posicionarse como la primera economía de África, ya que representa el 35\% del PIB subsahariano (Ministerio de Asuntos Exteriores y de Cooperación de España, 2019), ha enfrentado una serie de retos para el afianzamiento de este crecimiento, entre los que se destacan la influencia desastrosa que Boko Haram ejerce sobre el desarrollo económico; la repartición inequitativa de los recursos; la corrupción institucional; y los conflictos internos de carácter religioso y étnico.

Haciendo un análisis retrospectivo de los factores que determinaron el surgimiento y la evolución de Boko Haram en el seno de la comunidad musulmana nigeriana, es posible inferir que las reivindicaciones realizadas por esta organización, así como sus pretensiones unificadoras, encuentran sus raíces más profundas en el pasado colonial del país y en las dinámicas posteriores a su proceso de independencia.

Esto, ya que el trato diferenciado que recibieron las regiones, por parte del modelo indirect rule británico, favoreció al sur del país en diferentes aspectos, de manera que el norte nunca tuvo un papel preponderante en el marco de la política nacional (Duverne, 2005, p. 3). De hecho, hasta el 2015, año en 
que fue elegido el actual presidente musulmán de Nigeria, Muhammadu Buhari, los mandatarios del país habían sido cristianos (Ministerio de Asuntos Exteriores y de Cooperación de España, 2019, p. 3).

Como señala Loimeier (2012), Boko Haram no es el primer movimiento yihadista en la región que ha acudido a la guerra santa como estrategia para implementar un programa de reforma, pues, a comienzos del siglo XIX, Usman dan Fodio, quien falleció en 1817, inició un movimiento yihadista que condujo a la eliminación de los gobernantes habe en Hausaland y al establecimiento de la regla de eruditos religiosos que se esforzaron por legitimar esta a partir de la argumentación teológica.

Este personaje $^{3}$, considerado por su pueblo como injusto y desviado, fue un místico, filósofo y reformista que convocó a la yihad librada entre 1804 y 1808 contra el poder hausa, logrando establecer un nuevo Estado musulmán, el califato de Sokoto, que sobrevivió durante aproximadamente un siglo (Torres, 2015).

Si bien es cierto que la creación del califato trajo consigo una bonanza económica significativa por un tiempo relativamente largo, las prácticas corruptas y arbitrarias del régimen, que alcanzaron su máximo auge hacia finales del siglo XIX, generaron diferentes facciones y rivalidades internas, las cuales fueron aprovechadas por el imperio británico para invadir dicho territorio a inicios del siglo XX e incluir al califato, que se había conformado en el noroeste del país, en su sistema colonial.

Esto significó el fin de dicho sistema político que, sin embargo, permaneció en el imaginario musulmán de la zona como un legitimador de la yihad ante conductas desviadas por parte de los gobernantes, como la inquina colonial hacia la cultura y las costumbres locales que giraban en torno al islam.

Al respecto, Loimeier (2012) advierte que la argumentación teológica se convirtió desde entonces en la condición fundamental para la acción política de los musulmanes del norte de Nigeria, en tanto que

3 Los hausas constituyen el mayor grupo étnico de África occidental; se encuentran ubicados, principalmente, en el norte de Nigeria y el sureste de Níger, aunque también habitan ciertos territorios de Chad, Costa de Marfil, Camerún, Ghana y Sudán. 
la introducción de la educación occidental, como está simbolizada en los libros (Hausa: Boko) de las escuelas coloniales británicas, ha desafiado seriamente la posición hegemónica de la educación islámica y, en consecuencia, ha sido percibida como una amenaza y un símbolo del creciente impacto de un proceso de occidentalización ajeno, colonial, cristiano, materialista y corrupto. (p. 139, la traducción es mía) ${ }^{4}$

Tanto así que, antes de la aparición de Boko Haram, tuvo lugar el surgimiento de otro grupo sectario, igualmente de origen fundamentalista islámico, denominado Yan Tatsine, que era dirigido por el predicador Maitatsine y causó desórdenes durante varios meses en el territorio de Kano, al norte del país a finales del siglo XX (Torregrosa et al., 2016).

\section{Boko Haram y el conflicto nigeriano}

Luego de la consolidación de la democracia en Nigeria a finales del siglo XX, un movimiento islámico de carácter sunita fue fundado, en el año 2002, en la ciudad noreste de Maiduguri por el imam Mallan Muhammad Yusuf, bajo la premisa de denunciar la educación, la cultura, la fe y la democracia occidentales, como pilares pecaminosos que no debían regir la sociedad nigeriana.

Aunque dicha organización nació como un grupo de musulmanes devotos que se reunían para escuchar los sermones de Yusuf, más no como una organización de carácter insurgente o terrorista, como se le denominó posteriormente, el carisma de su líder fundador atrajo a un sinnúmero de seguidores que comenzaron a replicar su mensaje y postura ideológica, diseminando su doctrina en varias regiones al norte del país (Aguwa, 2017).

En diciembre de 2003, las inconformidades del imam, asociadas al carácter secular de la educación en Nigeria y a la corrupción de las instituciones estatales (Loimeier, 2012) se tradujeron en un conflicto abierto contra el Gobierno nigeriano, cuyas primeras acciones tuvieron lugar en 2004, cuando un grupo de seguidores de Yusuf perpetraron un ataque a las instalaciones de la Policía.

4 Texto original en inglés: "The introduction of Western education, as symbolized by the books (Hausa: boko) of British colonial schools, has seriously challenged the hegemonic position of Islamic education and has consequently been seen as both a threat and a symbol of the increasing impact of an alien, colonial, Christian, materialist and corrupt process of Westernization” (Loimeier, 2012, p. 139). 
Esto supuso su denominación como el "Talibán nigeriano” por parte de los medios de comunicación nacionales, etiqueta que sus homólogos occidentales adoptaron rápidamente.

Unos meses más tarde, exactamente en septiembre de 2004, varios ataques contra las comisarías del Estado de Borno dieron como resultado un total de 27 "talibanes" dados de baja por el ejército nacional, mientras otros lograron huir hacia el país vecino de Camerún. En esa oportunidad, Yusuf logró escapar hacia Sudán y posteriormente a Arabia Saudita, donde logró reunirse con el vicegobernador del estado de Borno, Adamu Dibal, quien eventualmente coordinó su regreso al país poco tiempo después. (Arenas, 2018, pp. 38-39)

A mediados de 2009, el conflicto en Nigeria escaló debido a una serie de enfrentamientos entre las fuerzas de seguridad y los seguidores de Boko Haram en los estados norteños de Kano, Borno, Yobe y Bauchi, dejando un saldo aproximado de 1000 muertos, entre ellos el líder de la organización quien habría sido asesinado al ser tomado como prisionero (Loimeier, 2012). En consecuencia, el mando de esta fue asumido temporalmente por Mallam Sanni Umaru, con lo que se dio inicio al uso de tácticas de lucha aún más violentas, haciendo que el conflicto alcanzara nuevas dimensiones entre 2011 y 2012.

Entre 2002 y 2009, Boko Haram concentró sus esfuerzos hacia una mayor visibilización y prevalencia política y cultural de los estados del norte, así como una redistribución más equitativa de los recursos derivados de la industria petrolera en Nigeria, todo ello mediante una estrategia de instrumentalización de la violencia.

Sin embargo, fue a partir de la desaparición de su líder y fundador, Mohamed Yusuf, que la organización inició su proceso de consolidación en el país, comenzando una campaña de expansión hacia los estados antes mencionados; hecho que impulsó la diversificación de sus tácticas militares, la ampliación de sus repertorios de violencia y, por consiguiente, un mayor impacto material y psicológico en la población civil (Walker, 2012).

En agosto de 2011, cuando los ataques a comunidades cristianas y poblaciones fronterizas se habían hecho cada vez más frecuentes, Boko Haram perpetró un ataque suicida en el edificio de Naciones Unidas en Abuja, dejando un saldo de 25 víctimas fatales (Elden, 2014), de manera que el conflicto comenzó a adquirir un carácter internacional. 
Toda vez que la yihad había sido declarada, con el objetivo de islamizar a Nigeria y asegurar un gobierno de mayoría musulmana, Abubakar Shekau asumió el mando definitivo de la organización, anunciando su meta de establecer un califato en el noroeste del país, tras lo cual Boko Haram comenzó a tomar pueblos y ciudades en los Estados de Adamawa, Yobe y Borno, imponiendo reglas severas y estricto cumplimiento de la sharía (Aguwa, 2017).

Ahora bien, para alcanzar dicho objetivo, Boko Haram empezó a buscar apoyo internacional, identificándose abiertamente con movimientos yihadistas en Irak, Afganistán, Indonesia, Pakistán, Yemen y Malí; además, inició un plan de expansión hacia países vecinos, estableciéndose en el Bosque de Sambisa, cuya área se extiende a zonas fronterizas con Chad y Camerún.

Esta última estrategia le permitió a la organización repeler los ataques de las tropas nigerianas, obteniendo así un amplio margen de ventaja, ya que, aparte de empezar a entrenar a sus hombres para la yihad en un territorio relativamente seguro, comenzó a recibir financiación del extranjero.

Además de perpetrar ataques terroristas contra comunidades enteras, exterminando mujeres, niños, hombres y ancianos, el 14 de abril de 2014 se presentó uno de los acontecimientos más representativos del avance terrorista de la Boko Haram, cuando "militantes de la organización secuestraron a 276 niñas cristianas en Chibok, Nigeria, para usarlas como esclavas sexuales y convertirlas mediante el uso de la violencia al islam" (Arenas, 2018, p. 40).

Este acontecimiento, que fue objeto de críticas y condenas por parte de la comunidad internacional — aunque de forma transitoria—, puso en evidencia la incapacidad de las autoridades nigerianas de hacer frente a la amenaza, puesto que, tras de permanecer impune en dicha ocasión, Boko Haram continuó perpetrando acciones terroristas a lo largo y ancho del país, sin obtener mayor resistencia.

De acuerdo con el Institute for Economics and Peace (citado por Pricopi, 2016), en el ańo 2014 Boko Haram perpetró 9 de los 20 ataques terroristas más fatales alrededor del mundo, con un promedio de 14 muertes por cada uno. De igual manera, en ese mismo año la organización generó el $80 \%$ de las muertes por terrorismo en Nigeria, lo que significó un aumento del 300\% en asesinatos de este tipo, la mayor cifra registrada por encima de cualquier país durante ese periodo. 
Así las cosas, "Nigeria llegó a ser el segundo país con mayor número de muertes relacionadas con el terrorismo en el mundo, siendo superado solo por Irak, un país desgarrado por la guerra, las insurgencias y la violencia sectaria” (Pricopi, 2016, p. 41).

Ahora bien, para el 2015 el Índice Global de Terrorismo determinó que esta organización era el grupo terrorista más letal del mundo, incluso por encima de Estado Islámico y, sin embargo, tal posicionamiento a escala global no significó una respuesta efectiva "ni por parte de Naciones Unidas, ni por parte de los principales Estados del Sistema Internacional, que asistieron pasivos a su proceso de consolidación entre 2009 y el año referido" (Arenas, 2018, p. 7).

Al respecto, vale aclarar que aunque Boko Haram inició sus actividades en el norte de Nigeria, poco a poco se fue extendiendo hacia los países vecinos, lo que da luces sobre el carácter de esta organización, toda vez que su intención totalizante y totalizadora sobrepasa el marco geográfico de referencia del norte nigeriano, mayoritariamente musulmán, para buscar la creación de un Estado islámico que logre "purificar" la política y las instituciones que, a su modo de ver, fueron corrompidas por influencias negativas arraigadas en Occidente. De allí que el nombre de la organización en lenguaje hausa ${ }^{5}$ pueda ser traducido como "western education is forbidden" 6

\section{Actores e intereses involucrados}

En el marco del conflicto nigeriano, existe una amplia variedad de actores, tanto del orden nacional como del orden internacional, algunos de los cuales tienen posiciones diametralmente opuestas.

5 Lengua chádica occidental hablada principalmente en Níger y en Nigeria.

6 Aunque la palabra boko ha sido entendida como "libro de aprendizaje", los lingüistas concuerdan en que la traducción más apropiada para este vocablo es "falso"; por otra parte, haram significa "prohibido" o sacrilegio, en lugar de pecado. De allí que con frecuencia la expresión Boko Haram sea traducida como "la educación occidental está prohibida", aunque dicha locución tiene una repercusión más amplia por cuanto atańe a los valores occidentales, o "aquellos quienes toman el dinero occidental y no actúan con caridad hacia los demás”, es decir la élite (Yan Boko) creada por la política de gobierno indirecto que usaron los británicos para colonizar Nigeria. En este sentido, "la occidentalización está prohibida" podría considerarse una expresión más cercana a su verdadero significado, pues hace alusión a las personas espiritual y moralmente corruptas, carentes de piedad religiosa y culpables de enriquecerse criminalmente en vez de dedicarse a la umma (comunidad) musulmana (Elden, 2014, p. 415). 
Por una parte, en el ámbito nacional se encuentran las fuerzas gubernamentales lideradas por el People's Democratic Party (PDP), que han estado en el poder desde la reinstauración de la democracia en 1999; de otro lado, la insurgencia terrorista de Boko Haram, que se afincó en el norte del país. Son estos, entonces, los dos principales actores protagonistas de las confrontaciones internas.

Ahora bien, debido a que en 2015 el conflicto adquirió una dimensión internacional, al escenario conflictivo se sumaron otros actores que ejercieron gran influencia en la evolución de las hostilidades, tales como países vecinos afectados por el fenómeno (Níger, Camerún, Chad y Benín); algunos Estados preponderantes del sistema internacional; y la comunidad internacional, en cabeza de Naciones Unidas.

\section{People's Democratic Party (PDP)}

Desde el restablecimiento de la democracia en 1999, y tras década y media de sucesivos regímenes militares, la escena política de Nigeria estuvo dominada por el PDP, un partido político fundamentado en una ideología de liberalismo económico y conservadurismo social que, en la práctica, es un defensor moderado de la libertad religiosa y la autonomía estatal (Ministerio de Asuntos Exteriores y de Cooperación de España, 2019).

Como ya se dijo, en el año 2000 algunos estados del norte de Nigeria introdujeron la ley islámica en sus territorios, lo que desencadenó una violencia sectaria en los estados de Kaduna y Abia. Sin embargo, el gobierno federal, liderado por el PDP, se negó a ceder a la presión de los estados del sur de mayoría cristiana - para derogar dicha ley, y, por el contrario, asumió el compromiso de aplicar la ley islámica solamente a los musulmanes.

En mayo de 2007, Umaru Musa Yar’ Adua se convirtió en el cuarto presidente constitucional de la República de Nigeria, quien, tras su fallecimiento en 2010, fue sucedido por su vicepresidente Goodluck Jonathan, quien, a su vez, fue reelegido en las elecciones de abril de 2011 y renovó su candidatura para las elecciones de 2015. Aunque en esta última oportunidad fue derrocado por Muhammadu Buhari, actual presidente de Nigeria, a quien se le han atribuido varias masacres contra musulmanes ${ }^{7}$.

7 "La victoria electoral de Buhari permitió por primera vez en la historia del país, un cambio de gobierno pacífico y democrático" (Ministerio de Asuntos Exteriores y de Cooperación de España, 2019, p. 3). 
A pesar de que las elecciones de 2011 fueron catalogadas como las más transparentes realizadas en décadas, la reelección del presidente dio origen a la gestación de una aguda violencia poselectoral, sobre todo en las regiones del norte, que se negaban a aceptar la victoria de Jonathan. En estos eventos se reportaron más de 800 muertes, muchas de las cuales fueron responsabilidad de Boko Haram, que se oponía vehementemente al mandato del cristiano del sur (González, 2016).

\section{All progressives Congress (APC)}

En un escenario de inseguridad en el norte del país, la nueva alianza política All progressives Congress (en adelante APC) en cabeza de Muhammadu Buhari, ganó las elecciones de 2015, lo que indicó un cambio de correlación de fuerzas dentro de Nigeria, producto de la derrota del PDP. De acuerdo con González (2016), el APC obtuvo casi el 53\% de los votos, en 20 de los 36 estados que conforman el país; mientras que el PDP se quedó con el 45\% y 15 de los estados.

Si bien es cierto que el traspaso de poderes se dio de forma pacífica, contrario a lo que se esperaba por las posturas diametralmente opuestas de ambos candidatos, Muhammadu Buhari heredó un país con una profunda crisis económica y social, debido a los brotes de violencia entre las diferentes etnias y a la depresión en el mercado petrolero internacional, lo que afectó gravemente la economía nigeriana que sigue siendo fundamentalmente rentista y dependiente de los mercados internacionales.

Adicional a esto, el nuevo presidente se vio obligado a hacer frente a la amenaza de Boko Haram que seguía azotando el norte del país, hecho que constituía un reto significativo, pues a pesar de que las fuerzas armadas nigerianas son una de las más fuertes de África occidental, estas se habían mostrado incapaces de controlar la situación de inseguridad, lo que se tradujo en la disminución de su liderazgo militar en el área.

Sin embargo, la experiencia de Buhari, quien era un general retirado, le permitió infundir una nueva dinámica al aparato militar, iniciando acciones más concretas para combatir a Boko Haram, cuyos líderes intentaban, en vano, fortalecer la organización (González, 2016). 
El logro más importante de esta nueva estrategia fue la conformación de la Fuerza Multinacional de Acción Rápida (Multinational Joint Task Force, en adelante MNJTF), en tanto que permitió la "derrota técnica" de Boko Haram, aunque en la práctica la agrupación no ha sido neutralizada todavía.

\section{Fuerzas armadas nigerianas}

Como ya se dijo, dentro de la subregión del África occidental las fuerzas armadas nigerianas gozan de cierto reconocimiento por sus capacidades militares, que se vieron disminuidas a raíz de la consolidación de Boko Haram, sin embargo, lograron reinventarse durante el gobierno de Buhari, quien impulsó la conformación de la MNJTF, gracias a la cual fue posible replegar y reducir las áreas bajo control de Boko Haram.

No obstante, aunque las fuerzas armadas de Nigeria (incluida la Armada Nacional, la Fuerza Aérea y el Ejército) contaban en 2019 con más de 162.000 efectivos, el país ha sido salpicado en los últimos años por numerosos conflictos internos, algunos de ellos de gran magnitud como, por ejemplo, el asunto de Boko Haram; el conflicto del delta del Níger; el separatismo de la región de Biafra; la piratería en el golfo de Guinea; la violencia entre pastores y agricultores; la violencia entre cristianos y musulmanes en el "cinturón medio"; el asunto de los chiitas entre a mayoría sunita; y otros conflictos menores que cobran un número importante de víctimas año tras año (Santé, 2017) ${ }^{8}$.

En el caso, por ejemplo, del conflicto del delta del Níger, cuyo escenario principal es el sur del país, este se agudizó con la derrota de Jonathan, lo que significó la reanudación de las acciones de grupos armados al margen de la ley, ya que en esta región no se han eliminado las condiciones objetivas que alimentan el conflicto, entre ellas los sentimientos nacionalistas y separatistas de la población igbo.

De allí, que haya emergido un nuevo grupo denominado Niger Delta Avengers (NDA), el cual, desde febrero de 2016, ha sido el responsable de la disminución de los volúmenes de producción de crudo, a raíz de los ataques contra oleoductos y plataformas de extracción (González, 2016).

8 Para más información sobre los conflictos allí mencionados, véase Santé (2017). 
Sin embargo, el surgimiento de grupos armados no es la única problemática que enfrenta el Estado desde el punto militar, a ello se suman la falta de garantías para el ejercicio y la protección de los derechos de la población civil, lo que se sustenta en numerosas acusaciones sobre los abusos en contra de los derechos humanos de la población por parte de las Fuerzas Armadas nigerianas.

En este sentido, parte de las razones que explican la agudización del conflicto con Boko Haram y otras organizaciones insurgentes, son las ejecuciones extrajudiciales de sus líderes, colaboradores inmediatos y civiles, así como las "acusaciones de tortura de supuestos sospechosos que, aunque en determinados casos hayan supuesto el inicio de alguna investigación, nunca han dado lugar al procesamiento de responsable alguno" (Santé, 2017, p. 111).

\section{Boko Haram}

Si bien es cierto que el surgimiento de Boko Haram se ubica en el año 2002, bajo el auspicio del líder musulmán Mohamed Yusuf, Beatriz Mesa (citada por Santé, 2017) vincula su creación a las milicias financiadas por el dictador Sani Mohamed Abacha en la década de los noventa, con la intención de establecer una fuerza capaz de contrarrestar un posible golpe de Estado por parte de las fuerzas armadas nigerianas.

Aunque para ese entonces Yusuf jugó un rol de líder espiritual de las milicias mediante una discursiva salafista", la cual estaba basada en "un discurso religioso sobre la necesidad de imponer la ley islámica como solución a la pauperización y la corrupción” (Santé, 2017, p. 10), para mediados de 2014, cuando la organización perpetró un ataque suicida en el cuartel general de las Naciones Unidas en Abuja, Boko Haram ya controlaba una gran extensión del territorio de Nigeria, gracias al legado de este líder que fue infravalorado por el gobierno anterior al del presidente Goodluck Jonathan.

9 El salafismo tradicionalista se concentra no solamente en la pureza de la doctrina, sino además en la predicación con vistas a reforzar la fe, "preservar la cohesión de la comunidad y defender el orden moral islámico, un discurso que coincide con el activismo fundamentalista y promueve la ortopraxia y con ello, como todo discurso de renovación, la ruptura con los musulmanes más tibios” (FernándezMontesinos, 2014, pp. 22-23). 
No obstante, el secuestro de las niñas de Chibok, durante el mandato de Jonathan, despertó una alarma mundial que llevaría al presidente a aceptar las ayudas de Estados Unidos, Reino Unido e Israel, y a coordinar alianzas con los países vecinos para contrarrestar esta amenaza, las cuales se vieron materializadas en el año 2015, bajo el mandato del presidente Buhari, en un acuerdo firmado con Camerún, Níger, Chad y Benín para la conformación de una fuerza multinacional conjunta cuyo objetivo era eliminar a Boko Haram como grupo armado.

Ahora bien, aunque es posible afirmar que en la actualidad esta organización se ha ido degradando ante la presión militar de Nigeria y otros países involucrados en la lucha conjunta, también es válido resaltar que Boko Haram continúa manteniendo su capacidad para perpetrar atentados masivos, así como ataques esporádicos a gran escala; tanto así que para finales de 2017 el conflicto había dejado un saldo más de 20.000 víctimas y cerca de 2 millones de desplazados en todo el territorio (Santé, 2017).

\section{Estados africanos afectados por el fenómeno}

A mediados de 2014, las naciones de Chad, Camerún, Níger y Nigeria acordaron formar una fuerza conjunta para combatir la creciente amenaza de Boko Haram, con una contribución inicial de 700 efectivos por país, es decir, un total de 2800 soldados, los cuales serían ubicados en las zonas fronterizas más afectadas por la violencia (BBC Mundo, 2014).

Dicha coalición tuvo su materialización en enero de 2015, gracias al liderazgo de los organismos regionales, a la presión internacional y al bloqueo de importantes rutas de abastecimiento e intercambio comercial, así como a la amplitud y virulencia de los ataques terroristas de Boko Haram, "cuyo radio de acción sobrepasó los límites del norte de Nigeria, extendiéndose hacia zonas fronterizas de Camerún, Níger y Chad” (Faus, 2015).

A su vez, en agosto de 2015 Benín se unió al mandato anterior, lo que dio paso a la creación de la ya mencionada MNJTF, con sede en Chad, conformada por 8700 efectivos de todos los países (La Información, 2015).

Según un informe emitido por el Consejo de Paz y Seguridad de la Unión Africana el 29 de enero de 2015, la Fuerza de Tarea Conjunta Multinacional 
contra Boko Haram (MNJTF por sus siglas en inglés), creada bajo el auspicio de la Comisión de la Cuenca del Lago Chad (LCBC por sus siglas en inglés), tiene como mandato crear un ambiente seguro en las áreas afectadas por Boko Haram y otros grupos terroristas, con miras a reducir la violencia en todas sus expresiones; facilitar la implementación de programas de estabilización general por parte de los Estados miembros en las zonas afectadas; y facilitar las operaciones humanitarias, así como la prestación de asistencia a las poblaciones afectadas (Arenas, 2018, p. 41).

Dentro de las principales motivaciones que llevaron a estos países a conformar la MNJTF, cabe destacar los intereses económicos de Chad, que al no tener salida al mar depende de la autopista que une la costa Duala (Camerún) con Djamena, siendo esta carretera una de las vías de abastecimiento básico más importantes para el país, la cual se encontraba ocupada por Boko Haram.

Por su parte, Níger estaba siendo objeto de ataques terroristas en varias zonas de su territorio, lo que perturbaba el desarrollo económico del país, en especial las finanzas públicas, y ocasionó la inestabilidad del sureste, escenario principal de los enfrentamientos armados. Adicional a ello, en 2014 Boko Haram intensificó el reclutamiento de combatientes en la ciudad de Diffa, en el extremo sureste del país, quienes se unieron al movimiento atraídos por el dinero fácil y el evidente éxito de la organización (International Crisis Group, 2017, p. 38).

En el caso particular de Camerún, este país tardó en reaccionar a la amenaza yihadista debido, en gran medida, a las rencillas históricas con Nigeria, aunque a mediados de 2014 se vio obligado a unirse a la lucha conjunta contra la organización. Esto, ya que a inicios de marzo de ese año seis miembros de Boko Haram fueron asesinados en Wouri-Maro, lo que ocasionó un endurecimiento de la posición de la organización en el país, que en mayo de 2014 perpetró un ataque terrorista al campamento en construcción de la compañía china Sinohydro.

Estos hechos significaron la declaración de guerra por parte del Estado camerunés con el despliegue de más de 700 soldados como refuerzos en el Lejano Norte, lo que marcó el inicio de un sinnúmero de operaciones militares que a finales de 2015 habían dejado un saldo de por lo menos 1000 secues- 
trados, 125 muertos y más de 2000 heridos en las fuerzas del Estado; así como 2000 presuntos miembros de Boko Haram muertos y 970 arrestados; y 1400 muertos entre la población civil (International Crisis Group, 2016, p. 48).

Finalmente, Benín decidió unirse a la fuerza conjunta como una medida preventiva frente a la expansión de Boko Haram hacia su territorio, debido a que entre 2013 y 2014 los ataques terroristas en zonas fronterizas de Nigeria, Níger, Chad y Camerún se intensificaron. Sin embargo, algunos críticos del régimen de Boni Yayi, presidente de este país, afirmaron que la decisión obedecía a la necesidad de encontrar una excusa para posponer las elecciones presidenciales y perpetuarse en el poder, bajo la excusa de un estado de crisis por el posible lanzamiento de una huelga de Boko Haram en su territorio (The Economist, 2015).

\section{Estados preponderantes del sistema internacional}

A mediados de 2014, y como respuesta a la expansión de la amenaza terrorista de Boko Haram en África occidental, algunos Estados preponderantes del sistema internacional decidieron involucrarse en el plan diseñado por los países de la región para contrarrestar el accionar de la organización yihadista, a través de diversas contribuciones y motivados por intereses particulares de orden sociopolítico, económico y geoestratégico.

\section{Reino Unido}

A mediados de 2014, el Ministro de Exteriores inglés anunció el incremento de la cooperación hacia Nigeria en materia de ayuda militar y educativa, a través de un programa de entrenamiento en tácticas de lucha contra la insurgencia, y el acceso a educación de más de un millón de niños y niñas nigerianos (Europa Press, 2014). A través de estas iniciativas, Reino Unido fue uno de los primeros países en ofrecer ayuda a Nigeria, aunque dicha asistencia estaba restringida a un tipo de cooperación técnica enfocada en la transferencia de conocimiento, más no en la provisión de armamento, debido, principalmente, a la ausencia de garantías sobre su uso y destinación ${ }^{10}$.

10 Según el Ministerio de Defensa (citado por Arenas, 2018), el paquete de asistencia a Nigeria incluía capacitación y asesoramiento a las unidades militares desplegadas para combatir a Boko Haram, a 
Así pues, en ese año, Reino Unido hizo una contribución de 1.7 millones de libras esterlinas al Fondo Central de Respuesta de Emergencias de la ONU y los programas del Departamento de Protección Civil y Ayuda Humanitaria de la Comisión Europea en Nigeria; igualmente, aportó un millón de libras adicional al Comité Internacional de la Cruz Roja destinado a ayudas humanitarias (Foreign \& Commonwealth Office, 2015).

\section{Estados Unidos}

A inicios de mayo de 2014, EE. UU. envió un aproximado de 80 militares a la República de Chad para localizar a las niñas secuestradas por Boko Haram en la localidad de Chibok, al tiempo que iniciaba un acercamiento con Nigeria, aunque con cierto recelo de aumentar la cooperación, debido a los agudos problemas de corrupción que enfrentaba el país. Cinco meses después, el presidente Barack Obama anunció el envío a Camerún de aproximadamente 300 militares norteamericanos para garantizar la seguridad en la zona fronteriza, mediante el desarrollo de operaciones de vigilancia, reconocimiento aéreo e inteligencia (Faus, 2015).

A mediados de ese mismo año, el presidente Obama propuso la creación del Counterterrorism Partnerships Fund, el cual se destinó para "ayudar a las naciones asociadas a proteger sus fronteras, denegar el acceso a las Organizaciones Extremistas Violentas (VEO por sus siglas en inglés) y llevar a cabo operaciones de contra incursión para interceptar, interrumpir y destruir VEO" (Department of Defense Budget, 2016, p. 2, la traducción es mía) ${ }^{11}$.

Sin embargo, el interés fundamental de los Estados Unidos era establecer una fuerza militar en el golfo de Guinea, para frenar la presencia de China, que se ha convertido en el principal socio comercial de Nigeria y de Camerún. Allí cobra especial relevancia el hecho de que, por un lado, el golfo de Guinea es una zona de alto valor estratégico, ya que concentra las mayores reservas probadas de petróleo, después del golfo Pérsico; y, por otro lado, Camerún es

través del Programa de Equipos de Capacitación a Corto Plazo (STTT) del $2^{\circ}$ Batallón del Royal Anglian Regiment.

11 El texto original en inglés: "CTPF funds will be used to assist partner nations in securing their borders, denying access to VEOs, and conducting effective counter-incursion operations to interdict, disrupt, and destroy VEOs" (Department of Defense Budget, 2016, p. 2). 
un país que cuenta con reservas probadas de aproximadamente 200 millones de metros cúbicos de gas, y ostenta un subsuelo rico en minerales raros como cobalto, el titanio, níquel, uranio, oro y diamantes, entre otros. (Mil21, 2015).

\section{China}

Dado que Boko Haram comenzó a dirigir algunos de sus ataques a las instalaciones petroleras chinas en la frontera entre Nigeria y Camerún, más específicamente a una planta ubicada en la localidad de Waza (Camerún), su posición inicial de no intervenir en el conflicto cambió radicalmente a finales de 2015, cuando el embajador de China en Nigeria, Gu Xiaojie, anunció que el gigante asiático apoyaría a Nigeria en el área de recolección de inteligencia y capacitación de personal.

Este giro en la política exterior china respecto a Boko Haram, se debió no solo a la afectación de sus instalaciones en la zona azotada por el conflicto, sino también a la instalación de un cable submarino de fibra óptica que conectaría Camerún con Brasil a través de China Unicom, un operador chino de comunicaciones por móvil, inversión que constituye una apuesta significativa para China, de cara a su posicionamiento en el sector de las telecomunicaciones (Arenas, 2018).

\section{Rusia}

A comienzos de 2015, el embajador de Moscú y el presidente de Camerún firmaron un acuerdo de cooperación para el suministro de material militar sofisticado, artillería pesada incluidos misiles, protección aérea, sistemas de misiles antiaéreos, equipos, cañones y vehículos blindados, así como el envío de ayuda humanitaria para socorrer a las víctimas de los atentados perpetrados por Boko (The Moscow Times, 2015).

$\mathrm{Su}$ creación fue motivada por los intereses rusos en este país por su cercanía física con Guinea Ecuatorial, Estado con el cual, a finales de 2015, el presidente Vladimir Putin firmó un acuerdo que autorizaba a la Armada rusa a disponer de sus puertos, para llevar a cabo operaciones de mantenimiento de los buques de guerra rusos. De allí, que Rusia haya prestado apoyo a Camerún y no a Nigeria, que era el epicentro del conflicto armado. 


\section{Francia}

Si bien es cierto que Francia había prestado un apoyo importante a la Fuerza Multinacional conformada por Níger, Nigeria, Chad, Camerún y Benín, incluyendo vuelos de vigilancia para monitorear los movimientos de Boko Haram, su interés en esta organización se hizo más notorio en marzo de 2015, cuando Boko Haram juró lealtad al Estado Islámico. Esto condujo a una reunión privada entre el presidente de Nigeria y François Hollande, con el fin de fortalecer los lazos de cooperación entre las dos naciones (O’Grady, 2015), los esfuerzos bilaterales para combatir la inseguridad marítima, en especial la piratería y el robo de crudo, y fortalecer las relaciones comerciales entre ambos países (Ministère de l'Europe et des Affaires Étrangéres, 2015).

Sin embargo, de acuerdo con el Institute for Security Studies, el llamamiento a Francia para ayudar no fue una coincidencia, ya que este país tiene intereses en los yacimientos de petróleo del delta del Níger, los cuales se han visto amenazados por Boko Haram (Zounmenou \& Kane, 2014).

\section{Canadá}

Entre 2013 y 2014 el Gobierno de Canadá brindó ayuda militar a Nigeria, con el envío de un grupo de soldados del Regimiento Canadiense (CSOR) para entrenar a las fuerzas nigerianas en distintas habilidades militares; también envió aviones no tripulados y otros equipos militares, para apoyar a las autoridades del país africano en la localización y rescate de las nińas de Chibok.

De acuerdo con la Alta Comisión de Canadá en Nigeria, la asistencia para el desarrollo prestada por este país para la lucha contra el terrorismo de Boko Haram, que entre 2017 y 2018 alcanzó los 133.78 millones de dólares (High Commission of Canada in Nigeria, 2020), obedeció a razones de tipo humanitario, entre ellas la de defender los derechos de las mujeres y niñas, combatir la violencia de género, y proteger a la población civil afectada por la insurgencia, tanto en Nigeria como en países vecinos, respondiendo así a las necesidades humanitarias de los refugiados nigerianos y las comunidades de acogida en Camerún, Chad y Níger.

Sin embargo, más allá de los aspectos humanitarios, el interés canadiense en el continente africano obedece a los activos mineros y petroleros de 
compañías nacionales que operan en 39 países del continente, por lo que se ha posicionado como uno de los primeros centros de financiación para las empresas de exploración minera en África (Caballero, 2013). Esto podría explicar la cada vez más creciente presencia de tropas canadienses en el suelo africano, ya que, más allá de buscar la consolidación de la paz y la seguridad en África, los esfuerzos de Canadá están encaminados a garantizar el acceso de sus compañías a los codiciados recursos naturales que alberga el continente.

\section{Rol de las Naciones Unidas en el conflicto armado en Nigeria}

El 22 de mayo de 2014, un par de meses después del secuestro de Chibok, y varios años después del inicio de las hostilidades, que para entonces ya habían cobrado la vida de miles de personas en Nigeria y otros países de la región, "el consejo de seguridad de la ONU incluyó al grupo armado islamista Boko Haram en la lista de organizaciones consideradas como terroristas y sometidas a sanciones por sus vínculos con Al-Qaeda" (Milenio, 2014, párr. 1), decisión que fue adoptada por petición de Nigeria, a fin de aplicar medidas sancionatorias a la organización.

A pesar de que el conflicto se inicia en el año 2002, con el levantamiento de Boko Haram contra el Gobierno de Nigeria, solamente hasta el 2009 la Organización de Naciones Unidas, a través del portal UNNews Centre, manifestó su preocupación por la creciente ola de violencia sectaria en el país; y no fue sino hasta el 19 de enero de 2015 que emitió un comunicado oficial, presidido por la presidencia de la organización, en el que por primera vez expresó su profunda preocupación por la socavación de la paz y la estabilidad en África central y occidental a raíz de las actividades de Boko Haram (News Wires, 2015).

No obstante, el Centro de Noticias de la ONU no es un canal oficial por medio del cual la organización emita sus decisiones y directivas en torno a diversas problemáticas de índole internacional; según Arenas (2018), entre el $1^{\circ}$ de enero de 2009 y el 31 de diciembre de 2015 se publicaron 102 noticias sobre Boko Haram, la mayoría de las cuales fueron posteadas entre 2014 y 2015, es decir, cuando el fenómeno adquirió una dimensión internacional que afectaba los intereses de las grandes potencias, como se muestra en la tabla 1. 
Tabla 1. Publicaciones del Centro de Noticias de la ONU sobre Boko Haram entre 2009 y 2015

\begin{tabular}{|c|c|c|}
\hline Año & $\begin{array}{c}\text { No. de } \\
\text { publicaciones }\end{array}$ & Tipo de contenido \\
\hline 2009 & 2 & $\begin{array}{l}\text { La ONU manifiesta su preocupación por la creciente ola de } \\
\text { violencia sectaria. }\end{array}$ \\
\hline 2010 & 0 & N/A \\
\hline 2011 & 1 & La ONU condena ataques en Nigeria. \\
\hline 2012 & 2 & $\begin{array}{l}\text { La ONU advierte posibles crímenes contra la humanidad en } \\
\text { Nigeria y cifra la cantidad de muertos por conflictos inte- } \\
\text { rreligiosos en el país. }\end{array}$ \\
\hline 2013 & 7 & $\begin{array}{l}\text { La ONU expresa su preocupación por ola de violencia; } \\
\text { condena asesinatos de estudiantes y civiles; advierte sobre } \\
\text { primeros éxodos hacia Camerún y Níger; reitera su preocu- } \\
\text { pación por la posible comisión de crímenes de lesa huma- } \\
\text { nidad. }\end{array}$ \\
\hline 2014 & 39 & $\begin{array}{l}\text { La ONU expresa su preocupación por nuevos éxodos y por } \\
\text { la integridad de los refugiados que han huido de Nigeria; } \\
\text { repudia el asesinato de civiles en Nigeria; apoya vigilia por } \\
\text { las niñas secuestradas en Nigeria; llama a unir esfuerzos } \\
\text { contra Boko Haram y destaca los problemas que afronta } \\
\text { África occidental; incluye a Boko Haram en la lista de } \\
\text { grupos terroristas; por medio de su Consejo de seguridad } \\
\text { resalta la amenaza que representa Boko Haram e insiste en } \\
\text { la necesidad de recuperar a las niñas secuestradas; pide que } \\
\text { responsables de los atentados sean juzgados y habla de viola- } \\
\text { ción del derecho internacional. }\end{array}$ \\
\hline 2015 & 51 & $\begin{array}{l}\text { La ONU llama la atención sobre crisis económica y huma- } \\
\text { nitaria; manifiesta preocupación por la violación sistemá- } \\
\text { tica de derechos humanos; advierte sobre la vulnerabilidad } \\
\text { de los niños en el conflicto y condena violencia sistemá- } \\
\text { tica contra ellos; repudia ataques de Boko Haram contra la } \\
\text { población civil; habla sobre la importancia de los medios de } \\
\text { comunicación para combatir el terrorismo; advierte sobre } \\
\text { aumento sin precedentes de combatientes extranjeros; insta } \\
\text { a los Estados a luchar contra Boko Haram mediante la } \\
\text { conformación de una fuerza conjunta }\end{array}$ \\
\hline
\end{tabular}


Teniendo en cuenta esta información, se puede evidenciar que el rol de la organización durante los años más críticos de las confrontaciones se concentró en ejercer una labor de monitoreo y seguimiento a los principales hitos y sucesos que marcaron el accionar de Boko Haram, mas no en hacer efectivo su mandato de velar por el mantenimiento de la paz y la seguridad internacionales, a través de los mecanismos con los cuales fue equipada desde su creación.

Ahora bien, con relación a estos mecanismos que constituyen los canales oficiales de la organización, entre 2002 y 2019 el Consejo de Seguridad emitió tan solo dos resoluciones que buscaron, por un lado, brindar un soporte jurídico al reconocimiento de Boko Haram como una organización terrorista asociada a Al-Qaeda, y, por otra parte, proveer un soporte jurídico para la conformación de una fuerza multinacional conjunta, dirigida a emprender acciones militares legítimas contra los integrantes de la insurgencia radical islámica, responsable de innumerables abusos y violaciones a los derechos humanos.

La primera de ellas fue la Resolución 2161, emitida el 17 de junio de 2014 tras la culminación de la $7198^{\mathrm{va}}$ reunión el Consejo de Seguridad, mediante la cual, actuando en virtud del Capítulo VII de la Carta de las Naciones Unidas, se toman medidas "respecto a Al-Qaeda y otras personas, grupos, empresas y entidades asociados con ella" (Consejo de seguridad, 2014), entre las cuales se destacan la congelación de activos, la prohibición de viajar y el embargo de armas.

Asimismo, en esta resolución se definen los criterios de inclusión en la lista de personas, grupos, empresas o entidades asociadas a Al-Qaeda, así como los procedimientos que se deben llevar a cabo para dicho fin, lo que implica un respaldo jurídico para la categorización de Boko Haram como organización terrorista $^{12}$.

$\mathrm{Al}$ respecto, cabe aclarar que esta resolución es producto de una reunión adelantada en París a mediados de mayo de ese mismo año, donde los presidentes de Nigeria, Chad, Camerún, Benín y representantes de Estados Unidos,

12 "Las Naciones Unidas (ONU) intentaron una definición de terrorismo en 2004 como "un acto destinado a causar la muerte o dańos corporales graves a civiles o no combatientes con el propósito de intimidar a la población u obligar a un gobierno o a una organización internacional a hacer o abstenerse de hacer cualquier acto" (Terewase, 2008, p. 318). Dicha definición es un poco limitada, por cuanto excluye la responsabilidad estatal, que también es una forma de terrorismo. 
Reino Unido y la Unión Europea, recomendaron a la ONU imponer sanciones internacionales a Boko Haram (La Información, 2014). Esto dio dio lugar a aquella declaración donde el secretario general de la ONU, Ban Ki-moon, denominaba a Boko Haram como una organización terrorista.

En segundo lugar, la Resolución 2349, emitida el 31 de marzo de 2017 tras la culminación de la $7911^{\text {va }}$ reunión del Consejo de Seguridad, hace referencia a la situación de conflicto en la región del Lago Chad, y a través de ella se reconoce la cooperación regional de los países de la Comisión de la Cuenca del Lago Chad (LCBC), mediante la conformación de una Fuerza de Tarea Conjunta Multinacional que reúne los esfuerzos, especialmente de Nigeria, Chad, Níger y Camerún.

Asimismo, en esta resolución el Consejo de Seguridad hace hincapié en diferentes aspectos sobre seguridad, protección de los civiles y los derechos humanos, asociados al conflicto procedente del norte de Nigeria, por ello:

1. Condena enérgicamente todos los ataques terroristas, las violaciones del DIH y los abusos de los derechos humanos cometidos por Boko Haram y el EIIL en la región; además, pide que los responsables de dichos actos rindan cuentas y comparezcan ante la justicia.

2. Exhorta a las entidades pertenecientes a Naciones Unidas y a la Oficina de las Naciones Unidas ante la Unión Africana (ONUUA) a redoblar su apoyo a los gobiernos de la región y a todas aquellas organizaciones subregionales y regionales, para hacer frente a los efectos de la violencia perpetrada por Boko Haram y el EIIL, así como a combatir las condiciones que propician la propagación del terrorismo y el extremismo violento.

3. Expresa su preocupación por las necesidades de protección de la población civil afectada por el flagelo del terrorismo, incluidas las derivadas de la violencia sexual, las ejecuciones extrajudiciales, la tortura, el reclutamiento y la utilización de niños, ente otras.

4. Reitera que los Estados tienen la responsabilidad de proteger a la población civil en sus territorios.

5. Promueve la cooperación militar regional para intensificar los esfuerzos dirigidos a luchar contra Boko Haram y el EIIL. 
Además de estos aspectos, la resolución hace especial énfasis en los asuntos humanitarios, entre los cuales se destaca la asistencia humanitaria por un valor de 458 millones de dólares, que se prometió en la conferencia de Oslo para 2017, dirigida a impedir un mayor deterioro de la crisis humanitaria y comenzar a abordar las necesidades de desarrollo endémicas (Consejo de Seguridad, 2017). Igualmente, hace referencia a temas relacionados con las causas profundas del conflicto, el desarrollo, el desarme, la desmovilización, la rehabilitación y la reintegración, así como la rendición de cuentas.

Luego de revisar ambas resoluciones, es evidente el alcance limitado de las acciones adelantadas por Naciones Unidas frente a la amenaza que implica Boko Haram para África Occidental, pues estas solamente se enmarcan en algunas recomendaciones a los países implicados, y a algunas contribuciones voluntarias para la financiación de la lucha internacional contra esta organización terrorista.

Como bien lo afirma Angerbrandt (2017), más allá de reconocer a Boko Haram como asociado de Estado Islámico y Al-Qaeda, la atención del Consejo de Seguridad debería estar dirigida principalmente hacia la dinámica del área, pues es en la región del lago Chad donde se encuentran tanto las motivaciones como las soluciones para la insurgencia islamista.

"Si bien la cooperación militar a través de las organizaciones intergubernamentales [...] es importante para mantener la presión sobre Boko Haram, existe una necesidad particular de iniciar actividades regionales" (Angerbrandt, 2017, pp. 4-5) basadas en la cooperación para el desarrollo social y económico. Sobre este aspecto, cabe resaltar que cada país de la región ha formulado sus propios planes de desarrollo (Nigeria, por ejemplo, tiene el "plan Buhari") aunque debido a la complejidad de la situación regional, es necesario vincularlos, ya que se ha demostrado que las economías de la región están integradas (cuando se han cerrado las fronteras entre los países, la vulnerabilidad de las personas aumenta).

Es justamente en este ámbito donde se hace necesario fortalecer la participación de la ONU, a través de sus programas y agencias, ya que los conflictos que azotan al continente africano han dejado consecuencias devastadoras para la vida humana, resquebrajando por completo el tejido social. 
Sobre este particular, vale la pena mencionar que, a través de Unicef, Acnur, la ONU Mujeres y la OIM, Naciones Unidas llevó a cabo diversas estrategias para la protección de los refugiados, tales como la elaboración de informes para monitorear y denunciar la crisis humanitaria, la construcción de campamentos para albergar a los refugiados y prestarles asistencia humanitaria, a través de la provisión de alimentos y enseres para la satisfacción de sus necesidades básicas (Arenas, 2018).

Entre los principales aportes hechos por la organización en materia de asistencia humanitaria, se destaca un informe emitido por Unicef (2015), titulado Missing Childhoods: the impact of armed conflicto on Children in Nigeria and beyond, en el que alerta sobre el impacto devastador que el conflicto ha ocasionado para los niños de la región, ya que a raíz del secuestro de Chibook se duplicó la cantidad de menores (más de 800.000) que huyeron del país en un intento por salvar sus vidas, cruzando hacia la frontera con Chad, Níger y Camerún.

De igual manera, el informe revela que los menores fueron utilizados como combatientes en las filas de Boko Haram, y muchas niñas y mujeres fueron sometidas a trabajos y matrimonios forzados, siendo víctimas de violaciones. De allí que, durante 2015, Unicef haya intensificado su respuesta humanitaria ante la agudización de la crisis, estableciendo alianzas para proveer agua y servicios vitales de salud, restaurar el acceso a la educación y ofrecer tratamiento terapéutico a niños en condición de desnutrición, así como brindar asesoría y apoyo psicosocial a más de 60.000 niños y niñas víctimas del conflicto armado (Unicef, 2015).

Lamentablemente, y a pesar de contar con los mecanismos necesarios para llevar a cabo intervenciones o tomar acciones específicas que ayuden a erradicar la amenaza terrorista y las fuentes más profundas del conflicto armado en Nigeria, el papel de la ONU como armonizador de las iniciativas individuales se ha visto reducido a tareas administrativas y a la movilización de recursos para atender la crisis humanitaria. Esto, debido en gran medida a que sus decisiones se encuentran supeditadas a los intereses de los Estados y, particularmente, de los cinco miembros permanentes del Consejo de Seguridad.

Por ejemplo, en el año 2002 se estableció la Oficina de las Naciones Unidas para África occidental (Unowa), con el fin de hacer frente al conflicto transfronterizo de la región y contribuir al establecimiento de la paz y la 
seguridad. Sin embargo, este departamento ha limitado sus funciones a tareas diplomáticas y de acompañamiento, fundamentalmente.

Adicional a ello, la organización no cuenta con recursos propios, sino que depende de los aportes voluntarios de los Estados miembros, de manera que cualquier intervención implica gastos onerosos que sobrepasan las responsabilidades de la organización, lo que obliga a los Estados a asumir una mayor carga monetaria para el cubrimiento de las misiones.

Finalmente, como bien afirma Chantal De Jonge Oudraat (2000), la organización carece de personal permanente para nutrir las intervenciones dirigidas a la defensa de los derechos humanos y a combatir amenazas específicas, lo que dificulta el cumplimiento del mandato para el cual fue creada.

\section{Evolución y desarrollo del conflicto}

A lo largo de los últimos años, Boko Haram ha logrado la sofisticación de sus métodos para llevar a cabo ataques terroristas, en parte, amparado por sus relaciones cercanas con Al-Qaeda, que le ha brindado entrenamiento militar y asesoría en la creación y manejo de explosivos, obteniendo una ventaja significativa, ya que esta red compleja de terrorismo internacional ha logrado la ampliación de su actuación en ciertos territorios africanos (Torregrosa et al., 2016). Esto, sin duda alguna, constituye una preocupación en el ámbito internacional, debido a la amenaza que puede representar para el resto de los países que un grupo terrorista controle un Estado productor y exportador de petróleo.

Además, Boko Haram cuenta con una facción escindida: el Estado Islámico en África Occidental (ISWA), la cual se encuentra particularmente activa en la actualidad. Para 2019, cerca de 22.000 nigerianos continuaban desaparecidos como resultado del conflicto armado con el grupo terrorista (Europa Press, 2019).

Con relación al modus operandi de la organización, este ha ido sufriendo modificaciones a lo largo del tiempo, pasando de asaltos a individuos y poblaciones cristianas con el uso de armas cortas, al uso de explosivos complejos en atentados suicidas y armamento militar.

Asimismo, la organización basa su accionar en tácticas de guerrilla, que poco a poco han evolucionado hacia el asesinato en masa de objetivos 
poblacionales, lo que la ha llevado a convertirse en una organización impredecible y altamente peligrosa. De manera que "el conflicto resultante, en la actualidad, podría considerarse como una guerra civil propiamente dicha" (Torregrosa et al., 2016, p. 72).

Según Kyari Mohammed (citado por Torregrosa et al., 2016), la progresiva pérdida de sus miembros más antiguos y la introducción de nuevos seguidores ha sido el detonador en el cambio de estrategia de Boko Haram, de manera que, por ejemplo, ha introducido el secuestro dentro de sus prácticas habituales, aunque en principio sus fundadores rechazaban esta práctica. Esto, sumado a sus raíces provenientes del salafismo yihadista, ha dificultado las negociaciones con la organización, aunque a la fecha ha habido una serie de acercamientos con el Gobierno, ninguno de los cuales ha conseguido abrir un camino hacia la paz.

Así las cosas, el contexto sociopolítico de Nigeria sigue siendo el de mayor inestabilidad en la subregión de África occidental, debido a la permanencia de los grupos armados en la región del delta del Níger y a la proliferación de grupos violentos vinculados o no a Boko Haram. Este factor religioso de corte islámico se sigue considerando como la causa principal de la regionalización de los conflictos del norte, al afectar de forma directa a países limítrofes como Chad, Camerún y Níger.

Adicional a esto, el accionar de Boko Haram ha sido el punto de partida para la consolidación de distintas manifestaciones del crimen organizado, tales como el secuestro y contrabando de personas, la piratería y el tráfico ilegal de armas, actividades que constituyen la principal fuente de financiación de la organización terrorista.

Con relación a la crisis interna que atraviesa Nigeria, esta continúa siendo alimentada por la discrepancia entre las fuerzas políticas del país (musulmanes en el norte y cristianos en el sur), la cual no logró ser resuelta en los comicios de 2015. Al mismo tiempo, la incapacidad de las Fuerzas Armadas para hacer frente a las amenazas terroristas y controlar los brotes de violencia del país, ha llevado a un incremento de la intervención de las grandes potencias del sistema internacional, a través de una colaboración mixta extranjera que, sin embargo, no se inmiscuye en los asuntos internos, lo que quiere decir que su incidencia en el panorama político de Nigeria es moderada. 
Un problema adicional, que se ha ido agudizando cada vez más, corresponde a los procesos migratorios asociados al conflicto armado, los cuales continúan en aumento, en especial aquellos relacionados con las oleadas de refugiados y con los desplazamientos internos campo-ciudad.

Toda esta situación ha sumido a Nigeria en una crisis económica que afecta principalmente a los Estados del norte, así como al delta del Níger, mayor región petrolera del país, lo que ha llevado a varias comunidades a caer en la pobreza extrema. A esto se suma el deterioro medioambiental a causa de la explotación petrolera, que ha modificado varios ecosistemas, eliminando los medios de subsistencia de las comunidades de pescadores en la zona costera. "La situación ambiental y económica en esta parte del país influye de manera considerable en el desarrollo de grupos armados, los movimientos sociales y sindicales en la región" (González, 2016, p. 119).

Finalmente, con relación a los actores internacionales, Estados Unidos sigue siendo el principal socio económico de Nigeria, por su capacidad petrolera, así como su principal aliado, por sus capacidades militares, las cuales que ha venido empleando en las misiones de paz. Este país coordina su accionar con Reino Unido y Francia, con quienes comparte estrategias comunes en materia de lucha contra la corrupción y el terrorismo, al igual que en pro de la promoción de la democracia.

Por su parte, China, el gigante asiático, ha aumentado de forma considerable su nivel de participación en la economía nigeriana, especialmente en el sector de los hidrocarburos, construyendo infraestructura petrolera que ha resultado problemática para los intereses norteamericanos. De allí que ambas potencias hayan seguido de cerca el fenómeno terrorista de Boko Haram, que a la fecha sigue siendo una amenaza latente.

Para finalizar, dado que el conflicto armado en Nigeria alcanzó su momento más álgido entre 2014 y 2015, sin que ello signifique que el mismo ha finalizado, el accionar de Naciones Unidas se sigue reduciendo a un papel de verificación y asistencia a las víctimas, sin que se haya materializado ninguna acción concreta enmarcada en el capítulo VII de la Carta de San Francisco. 


\section{Referencias}

Aguwa, J. (2017). Boko Haram: History, Ideology, And Goal. The International Journal of Religion and Spirituality in Society, 7(2), 11-23.

Angerbrandt, H. (2017). Nigeria and the Lake Chad Region Beyond Boko Haram (Policy Note $\mathrm{N}^{\circ}$ 3). Nordic Africa Institute. http://www.diva-portal.org/smash/get/diva2:1115195/ FULLTEXT01.pdf

Arenas, A. (2018). Consolidación de Boko Haram en Nigeria entre 2009 y 2015: Un estudio de caso sobre la banalización del terrorismo [Tesis de maestría, Universidad Externado de Colombia].

BBC Mundo. (2014, julio 24). Cuatro países africanos crean fuerza conjunta contra Boko Haram. BBC Mundo. https:/www.bbc.com/mundo/ultimas_noticias/2014/07/140723_ ultnot_africa_boko_haram_fuerza_az

Caballero, C. (2013, mayo 22). Canadá también mete mano. El Pais. https://elpais.com/ elpais/2013/05/22/africa_no_es_un_pais/1369202460_136920.html?rel=mas

Consejo de Seguridad (2014). Resolución 2161. Naciones Unidas. https://undocs.org/es/S/ RES/2161(2014)

Consejo de Seguridad. (2017). Resolución 2349. Naciones Unidas. https://undocs.org/es/S/ RES/2349(2017)

Department of Defense Budget. (2016). Counterterrorism Partnersships Fund [Report]. https:// comptroller.defense.gov/Portals/45/Documents/defbudget/fy2017/FY2017_CTPF_JBook.pdf

Duverne, D. (2005). Aproximación a la situación politica y económica de Nigeria. Consejo Argentino para las Relaciones Internacionales. http://www.cari.org.ar/pdf/nigeria.pdf

Elden, S. (2014). The Geopolitics of Boko Haram and Nigeria's "War on Terror". The Geographical Journal, 180(4), 414-425.

Europa Press. (2014, junio 13). Reino Unido incrementa su apoyo a Nigeria para ayudarla contra Boko Haram. El Economista. https://www.eleconomista.es/africa/noticias/5858967/06/14/Reino-Unido-aumentara-su-ayuda-militar-y-educativa-a-Nigeriapara-ayudarla-contra-Boko-Haram.html

Europa Press. (2019, septiembre 12). Una década de conflicto en Nigeria con Boko Haram deja al menos 22.000 desaparecidos. Europa Press. https://www.europapress.es/internacional/noticia-decada-conflicto-nigeria-boko-haram-deja-menos-22000-desaparecidos-20190912131101.html

Faus, J. (2015, octubre 14). Estados Unidos envía a 300 militares a Camerún contra Boko Haram. El Pais. https://elpais.com/internacional/2015/10/14/actualidad/1444853250_884008. html

Fernández-Montesinos, F. (2014). Doctrina y acción política. Pugnas sobre el islam verdadero. El salafismo. En Ministerio de Defensa e Instituto Español de Estudios Estratégicos (Eds.), Documentos de Seguridad y Defensa 62. Yihadismo en el mundo actual (pp. 17-41). Ministerio de Defensa. https://dialnet.unirioja.es/servlet/articulo?codigo=4813624 
Foreign \& Commonwealth Office. (2015, March 12). Nigeria-Boko Haram and The Fight Against Terrorism. gov.uk. https://www.gov.uk/government/case-studies/nigeria-bokoharam-and-the-fight-against-terrorism

González, Y. (2016). Situación actual en Nigeria: tendencias socioeconómicas y políticas más probables hacia el 2020. Contra. Relatos desde el sur, (12-13), 109-125.

High Commission of Canada in Nigeria. (2020, March 9). Canada-Nigeria Relations. Government of Canada. https://www.canadainternational.gc.ca/nigeria/bilateral_relations_ bilaterales/canada_nigeria.aspx?lang=eng \&_ga $=2.97878810 .442009475 .1517357162$ 1235619368.1517106805

International Crisis Group. (2016). Cameroon: Confronting Boko Haram (Africa Report N. ${ }^{\circ}$ 241). International Crisis Group. https://d2071andvip0wj.cloudfront.net/241-cameroon-confronting-boko-haram_1.pdf

International Crisis Group. (2017). Niger and Boko Haram Beyond Counter-insurgency (Africa Report N. ${ }^{\circ}$ 245). International Crisis Group. https://d2071andvip0wj.cloudfront. net/245-niger-and-boko-haram-beyond-counter-insurgency.pdf

La Información. (2014, mayo 23). La ONU declara a Boko Haram como grupo terrorista. La Información.

La Información. (2015, julio 30). Nigeria, Níger, Chad, Camerún y Benín se unen contra Boko Haram. La Información. https://www.lainformacion.com/mundo/nigeria-niger-chad-camerun-y-benin-se-unen-contra-boko-haram_ZcpQyVS5Wa9CRh9SZ9Hau3

Loimeier, R. (2012). Boko Haram: The Development of A Militant Religious Movement in Nigeria. Africa Spectrum, 47(2-3), 137-155.

Mil21. (2015, octubre 19). Obama envía tropas a Camerún para frenar a China y Rusia en el golfo de Guinea con la justificación de combatir a Boko Haram. mil21. https://www. mil21.es/noticia/286/claves/obama-envia-tropas-a-camerun-para-frenar-a-china-y-rusiaen-el-golfo-de-guinea-con-la-justificacion-de-combatir-a-boko-haram.html

Milenio. (2014, mayo 22). ONU incluye a Boko Haram en lista de terroristas. Milenio. https:// www.milenio.com/internacional/onu-incluye-boko-haram-lista-terroristas

Ministère de l'Europe et des Affaires Étrangéres. (2015, septiembre 16). Joint communiqué following the official visit to France of the president of the federal republique of Nigeria, Muhammadu Buhari. Ministry for Europe and Foreign Affairs. https://www.diplomatie. gouv.fr/en/country-files/nigeria/events/article/joint-communique-following-the-officialvisit-to-france-of-the-president-of-the

Ministerio de Asuntos Exteriores y de Cooperación de España. (2019). Ficha País. República Federal de Nigeria. http://www.exteriores.gob.es/Documents/FichasPais/Nigeria_FICHA\%20PAIS.pdf

News Wires. (2015, January 20). UN Urges Military Action Against Boko Haram. France 24. https://www.france24.com/en/20150120-un-security-council-military-action-boko-haram-nigeria

O'Grady, S. (2015, September 15). France to Nigeria: It's All One Fight Against Boko Haram and the Islamic State. Foreign Policy. https://foreignpolicy.com/2015/09/15/france-to-nigeria-its-all-one-fight-against-boko-haram-and-the-islamic-state 
Oudraat, C. deJ.(2000). Intervention in InternalConflicts:LegalandPolitical Conundrums. Carnegie Endowment for International Peace. https://carnegieendowment.org/2000/08/10/intervention-in-internal-conflicts-legal-and-political-conundrums-pub-379

Pricopi, M. (2016). Tactics Used by the Terrorist Organization Boko Haram. Scientific Bulletin, 1(41), 40-45.

Santé, J. (2017). Nigeria, elenco de conflictos. Instituto Español de Estudios Estratégicos, 5, 100-119.

Terewase, I. (2008). Legal Framework for The Punishment of Terrorism in Nigeria: A Critique of The EFCC Establishment Act. The Nigerian Army Quarterly Journal, 4(3), 314-342.

The Economist. (2015, March 6). Fear of Boko Haram Activities in Northern Benin. The Economist - Intelligence Unit. https://country.eiu.com/article.aspx?articleid=1232941107\&Country=Benin\&topic $=$ Politics\&subtopic $=$ F_3

The Moscow Times. (2015, January 20). Russian Arms to Aid Cameroon's Fight Against Boko Haram. The Moscow Times. https://www.themoscowtimes.com/2015/01/20/russian-arms-to-aid-cameroons-fight-against-boko-haram-a43056

Torregrosa, F., López, R., Garriga, D., Sánchez, N., \& García, Á. (2016). Boko Haram: Análisis del fenómeno terrorista en Nigeria. Revista Criminalidad, 58(1), 67-79.

Torres, O. (2015). La gestación de una insurgencia: antecedentes históricos e ideológicos de Boko Haram en Nigeria. Grupo de Estudios en Seguridad Internacional (GESI). http://www. seguridadinternacional.es/?q=es/print/644

Unicef. (2015). Missing Childhoods: The Impact of Armed Conflict on Children in Nigeria and Beyond. Unicef. https://www.unicef.es/publicacion/missing-childhoods-impact-armed-conflict-children-nigeria-and-beyond

Walker, A. (2012). Special Report. What is Boko Haram? United States Institute of Peace. https:// www.usip.org/sites/default/files/resources/SR308.pdf

Zounmenou, D., \& Kane, M. (2014, March 11). Nigeria's Fight Against Boko Haram: How Can France Help? ISS Africa. https://issafrica.org/iss-today/nigerias-fight-against-boko-haramhow-can-france-help 